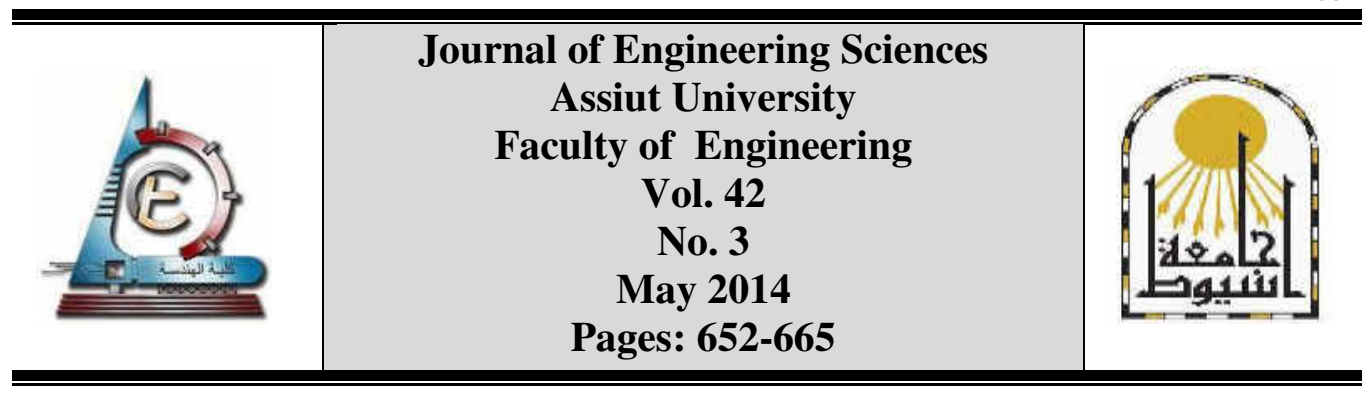

\title{
ROOF LATERAL DISPLACEMENT FOR GRAVITY LOAD DESIGNED RC FRAMES SUBJECTED TO EARTHQUAKES
}

\author{
Khairy H. Abdelkareem ${ }^{1}$ and N. AL-Mekhlafy ${ }^{2, *}$ \\ ${ }^{1,2}$ Civil Engineering Department, Faculty of Engineering, Assiut University
}

Received 1 April 2014; revised 27 April 2014; accepted 2 May 2014

\begin{abstract}
The roof lateral displacement for RC frames is very significant parameter in performance based engineering and should be within acceptable limits as per the requirement of different performance levels. Data obtained from the time history dynamic analysis for a series of gravity load designed (GLD) RC frame was used as input data in a statistical program called SPSS 16.0, and a statistical analysis was done and a power equations was proposed to estimate the roof lateral displacement for the GLD RC frames. Three equations were proposed for estimating the roof lateral displacement. The first one is for the bare frame models, the second is for infilled frame models and the third is for infilled frame with open ground story. The equations for estimating the roof lateral displacement for GLD frames with different type of infill (bare, infilled and open ground story models) are proved to be acceptable accuracy and they can be used to estimate the roof lateral displacement for GLD RC frames if they meet the conditions set out.
\end{abstract}

Keywords: gravity load designed, SPSS 16.0, frame models.

\section{Introduction}

Reinforced concrete (RC) framed structures are very common in many countries in the world, especially in developing countries, and are the predominant structural system in Arab Countries. In various parts of the world, especially in Arab World, reinforced concrete structures even in seismic zones have been designed only for gravity load. Such structures though performing well under conventional gravity load case, could lead to questionable structural performance under earthquake. In most cases, those structures are vulnerable to any major earthquake and so these structures need immediate assessment to avoid a collapse which brings a huge loss of human lives and economy that the world has witnessed for several times.

Masonry infill walls are frequently used as interior partitions and exterior wall in $\mathrm{RC}$ frames. Usually, the infill walls are treated as non-structural element and their influences on the structural response are generally ignored. Many RC buildings constructed in recent

\footnotetext{
* Corresponding author.

E mail address: nadmi216@yahoo.com
} 
times have a special feature, the ground story is left open for the purpose of parking (Fig.1), i.e., columns in the ground story do not have any partition walls (of either masonry or RC) between them. Such buildings are often called open ground story buildings. These buildings look as if they are supported by chopsticks! Open ground story buildings have consistently shown poor performance during past earthquakes across the world [1].

Recent earthquakes have clearly shown that the damages done to the buildings with infill were considerable less than those without infill and the difference was quite a bit significant. Therefore, the structural contribution of infill walls cannot simply be neglected particularly in regions of moderate and high seismicity where, the frame-infill interaction may cause substantial increase in both stiffness and strength of the frame. In fact, the interaction between the infill and the frame has a dual effect: it may or may not improve the seismic performance of the structure due to several reasons such as regular distribution and continuity of infill.

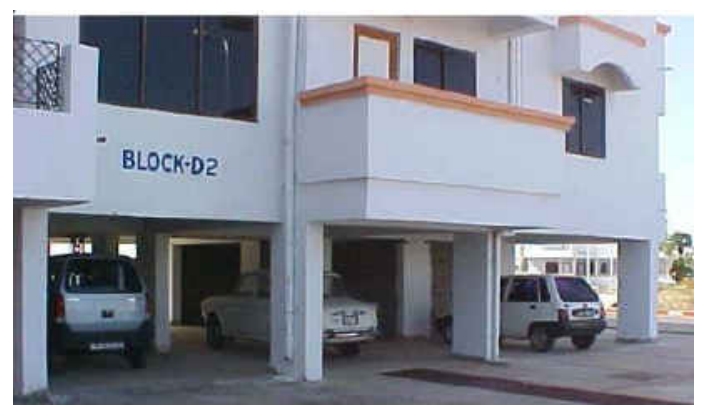

Fig. 1.Typical example of open ground story building[1]

Earthquakes are one of nature's greatest hazards to life on this planet. The impact of this phenomenon is sudden with little or no warning to make preparations against damages and collapse of buildings/structures. Recent earthquakes across the world, including the 1982 Dhamar earthquake in Yemen, the 1992 Cairo earthquake in Egypt, the 1995 Hyogoken Nanbu earthquake in Japan, the 1999 Izmit and Ducze earthquakes in Turkey, the 2001 Bhuj earthquake in India, the 2001 Chi Chi earthquake in Taiwan, the 2003 Boumerdes earthquake in Algeria, the 2009 Southern Sumatra in Indonesia, and the 2011 Van earthquake in Turkey revealed major seismic deficiencies in the RC buildings, some of which led to catastrophic collapses causing a death toll measured in thousands. One of the major causes of seismic vulnerability associated with these buildings is that, in the developing countries, a large number of the existing RC frame buildings have been designed to resist only vertical loads and had insufficient lateral resistance and the architects and engineers were without formal training in the seismic design and construction and have been built by inadequately skilled construction workers [1 - 6].

In the recent years, special attention has been given to the investigation on the seismic behavior of reinforced concrete buildings designed for gravity load only. Most of these structures have been typically designed and built before the introduction of adequate seismic design code provisions. In the Arab World, until late 1990s, there was no regulation to design and construct building structures for seismic resistance and most building structures were designed to resist gravity loads only (GLD), for example, in Egypt the first official code of practice to consider seismic loading was published by the Ministry of Housing in 1989 [3], and in Syria the seismic design for buildings was mandatory as a 
law in1997 [7]. Whereas, unfortunately, no building seismic codes are available for the Arabian Peninsula states [8] and Yemen [2].

Because there is a large inventory of buildings that were designed and constructed without considering the seismic loads, it is believed that many of these structures may pose an unacceptable life-safety hazard in the event of a major earthquake. Also non ductile detailing practice employed in these structures makes them prone to potential damage and failure during earthquake. This fact explains the basic need for identification of such buildings, the evaluation of their expected seismic performance, and if needed, their seismic strengthening.

The roof lateral displacement is very significant parameter in performance based engineering and should be within acceptable limits as per the requirement of different performance levels. Hence in this study, a focus is given to propose an expression for estimating the roof lateral displacement for RC frames designed for gravity load only (GLD) by using and analyzing the results obtained in a previous study [9] done by the authors for a series of GLD RC with different number of bays, different number of stories, different bay spanned three types of presences of infill (bare frame "BF", infilled frame "IN" and infilled frame with open ground story "OG"). The data will be analyzed using a statistical program called SPSS 16.0 in order to propose an expression to estimate the roof lateral displacement for three types of GLD RC; bare frame, infilled frame and infilled frame with open ground story.

\section{General description of SPSS 16.0 software}

The abbreviation SPSS16.0 stands for Statistics Package for the Social Sciences and is considered as one of the leading statistical software applications and it is probably the most popular general statistics packages in academia. The integration of the graphics module to the Base with excellent interface is just one example of the state of the art of the product[10].

SPSS is a Windows based program that can be used to perform data entry and analysis and to create tables and graphs. SPSS has scores of statistical and mathematical functions, scores statistical procedures, and a very flexible data handling capability. Some of the functionalities of SPSS are: Descriptive Statistics, Reliability tests, Correlation, T-tests, Regression and curve estimation.

The Curve Estimation procedure produces curve estimation regression statistics and related plots for 11 different curve estimation regression models. A separate model is produced for each dependent variable. You can also save predicted values, residuals, and prediction intervals as new variables. The curve estimation regression models are linear, logarithmic, inverse, quadratic, cubic, power, compound, S-curve, logistic, growth, and exponential.

\section{General description of models under study}

In our previous study [9], time history analysis was performed to study the effect of selected parameters in the behavior of reinforced concrete frames under earthquake loads. A series of multistory RC frames were designed for gravity loads only (1.4D.L+1.7L.L) without considering the seismic loads as typically found in most seismic prone countries before the introduction of adequate seismic design code provisions. All frame models have a constant $3 \mathrm{~m}$ story height except the ground story is $4 \mathrm{~m}$ (Fig.2). The parameters considered for each RC 
frame model under study are: number of stories $\left(" n_{1} "=2,4,6,8,12\right.$ and 16 stories), number of bays ( $\mathrm{n}_{2} "=1,2,3$, and 4 bays) and the bay span ("L" $=4,6$, and $8 \mathrm{~m}$ ) and three types of infill wall presence (without infill "BF", full infill "IN" and full infill with open ground story "OG") Fig.3. The detailing for the structure was in accordance with the general non-seismic provisions of the ACI 318-89 Code [11]. for more details see references [9] and [12]

It should be noted here that for differentiating between each models, a Model_ID was given for all models to describe the model's number of stories, number and span of bays and the type of infill. The Model_ID is composed of three parts, the first part consists of number followed by the letter "S" expresses the number of stories and the second part consists of letter "B" preceded by a number that represents the number of bays, where the number that follows the letter "B" represents the bay length, while the third part indicates the existence of masonry infill or not ("BF": without infill, "IN": full infill in all stories and "OG": open ground story and with infill in all others stories). For example, the ID (4S_3B6_BF) stands for model with four stories, three bays with six meter span and type of frame is bare frame.

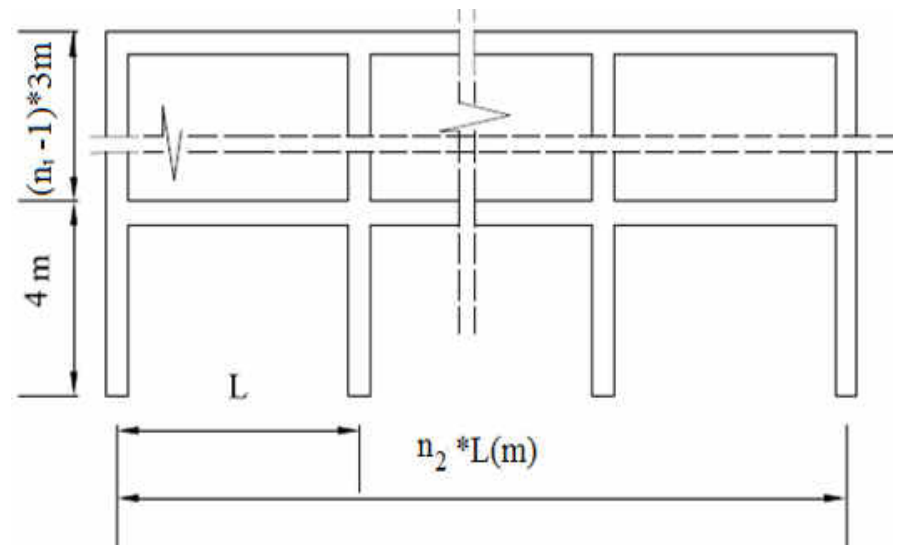

Fig. 2. RC frame models under study, where $" n_{1}$ " is the number of stories, $" n_{2} "$ is the number of bays and "L" is the bay span.

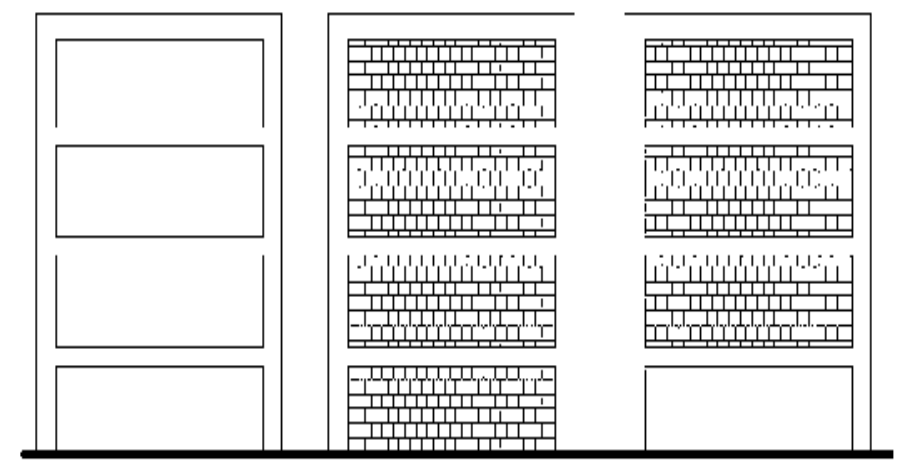

a) Bare Frame "BF" b) Full Infill "IN" c) Open Ground Story "OG"

Fig. 3. General Types of RC Frame under study according to presence of infill 
JES, Assiut University, Faculty of Engineering, Vol. 42, No. 3, May2014, pp. 652-665

\section{Data Input and statistical analysis}

The roof lateral displacements obtained from the time history dynamic analysis for models under study were listed in Table 1.

\section{Table 1.}

Roof lateral displacement for all models under study [9]

\begin{tabular}{|c|c|c|c|c|c|c|c|c|c|c|c|c|}
\hline \multirow{3}{*}{$\begin{array}{c}\begin{array}{c}\text { Number } \\
\text { of } \\
\text { Stories }\end{array} \\
\end{array}$} & \multicolumn{12}{|c|}{ Number of Bays and Frame Type } \\
\hline & \multicolumn{3}{|c|}{ One-Bay } & \multicolumn{3}{|c|}{ Two-Bay } & \multicolumn{3}{|c|}{ Three-Bay } & \multicolumn{3}{|c|}{ Four-Bay } \\
\hline & BF & IN & OG & BF & IN & OG & BF & IN & OG & BF & IN & OG \\
\hline 2 & 10.03 & 2.07 & 12.25 & 9.06 & 1.75 & 10.19 & 8.64 & 1.56 & 9.14 & 8.22 & 1.46 & 8.84 \\
\hline 4 & 17.49 & 9.82 & 14.83 & 15.49 & 9.46 & 12.42 & 14.44 & 8.47 & 11.82 & 13.61 & 8.04 & 11.40 \\
\hline 6 & 27.84 & 18.18 & 16.28 & 23.30 & 16.98 & 15.63 & 20.80 & 16.26 & 15.54 & 18.89 & 16.05 & 15.39 \\
\hline 8 & 55.15 & 38.20 & 41.37 & 48.61 & 27.57 & 30.22 & 41.82 & 22.84 & 26.39 & 38.57 & 20.01 & 22.39 \\
\hline 12 & 74.26 & 61.00 & 63.71 & 68.23 & 52.20 & 55.30 & 64.06 & 48.19 & 52.70 & 58.88 & 45.60 & 45.65 \\
\hline 16 & 108.3 & 91.09 & 78.73 & 94.76 & 78.89 & 61.33 & 84.82 & 70.95 & 48.80 & 78.94 & 65.26 & 51.73 \\
\hline
\end{tabular}

The data obtained from the analysis was used as input data in a statistical program called SPSS, and a statistical analysis was done, using the power curve estimation regression model, in order to propose a curve and equation to estimate the roof lateral displacement for the GLD RC frames subjected to earthquake. The estimation was done under the following condition:

- The reinforced concrete frame is designed for gravity load only without considering the seismic loads (no lateral loads were considered for the design).

- The specified strengths of the concrete and reinforcing steel are, respectively, $f_{c}$ $=21 \mathrm{MPa}$ and $f_{y}=400 \mathrm{MPa}$.

- The earthquake time history acceleration is the N-S EL-Centro 1940 with peak ground acceleration $0.31 \mathrm{~g}$.

- The masonry infill used is brick units with $100 \mathrm{~mm}$ width.

As discussed in previous study, it can be said that the roof lateral displacement is dependent on different parameters as follows:

- There is a positive correlation between the roof lateral displacement and the total height of the frame $\left(R L D \alpha \mathrm{H}_{\mathrm{t}}\right)$.

- There is an inverse correlation between the roof lateral displacement and the total width of the frame $\left(R L D \propto \frac{1}{L_{t}}, \frac{1}{n_{2}}\right)$.

- There is a positive correlation between the roof lateral displacement and the total dead loads for the frame $\left(R L D \propto \mathrm{DL}_{\mathrm{t}}\right)$.

- There is an inverse correlation between the roof lateral displacement and the total area of column sections at the base $\left(R L D \alpha \frac{1}{A_{c t}}\right)$.

In order to propose a curve and equation to estimate the roof lateral displacement for the GLD RC frames and with taking the effect of different parameters a parameter called " $\mathrm{X}$ " is assumed to involve the effect of the parameters under study as follow: 


$$
X=\sqrt{\frac{1}{n_{2}} \cdot \frac{H_{t}}{L_{t}} \cdot \frac{1}{\sum A_{c}}} * D L_{t}
$$

Where: $H_{t}$ is the total frame height in $(\mathrm{m}) ; n_{2}$ is the number of bays; $L_{t}$ is the total frame width in $(\mathrm{m}) ; \sum A_{c}$ is summation of columns section area at the base $\operatorname{in}\left(\mathrm{m}^{2}\right)$, and $D L_{t}$ is the total dead load $(\mathrm{KN})$ applied on the frame.

The parameter " $X$ " was calculated for all models under study and used with roof lateral displacement obtained as input data to the statistical program and a regression analysis was done to draw a curve of best fit through the data points for the models. These processes were done for the three cases of infill (Bare frame "BF", infilled frame "IN" and open ground story "OG" models). After drawing the curve of best fit the equation has been derived, it can be used to predict the change in roof lateral displacement " $R L D$ " for any change in X. It can therefore be used to extrapolate between the existing data points as well as predict results which have not been previously observed.

\section{Results and discussions}

\subsection{Estimating the roof lateral displacement for Bare Frame models}

For the bare frame models the curve of best fit for estimating the roof lateral displacement is shown in Fig.4. The corresponding correlation coefficient $\left(\mathrm{R}^{2}\right)$ was observed $=0.954$, and the equation is derived as power equation:

$$
\begin{gathered}
R L D_{B F}=0.12034 *\left(\sqrt{\frac{1}{n_{2}} \cdot \frac{H_{t}}{L_{t}} \cdot \frac{1}{\sum A_{c}}} * D L_{t}\right)^{0.8375} \\
R L D_{B F}=0.12034 *(X)^{0.8375}
\end{gathered}
$$

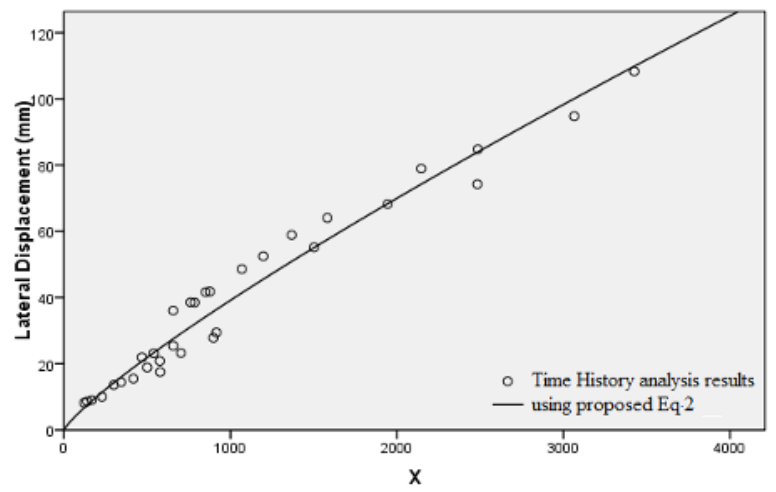

Fig. 4. Estimating the RLD for bare frame models.

Fig.5 and Table 2showthe correlation of estimated value by (Eq.2) with the obtained values, a comparison between the estimated and observed roof lateral displacement for bare frame models. It is observed that the equation (Eq.2)estimates the values quite accurately and not too far away from the analytical results and this proves the validity of the model. The slope of the trendline between the observed and estimated results was $0.984\left(\theta=44.54^{\circ}, \theta\right.$ is the angel between the trendline and the horizontal axis $)$. 
JES, Assiut University, Faculty of Engineering, Vol. 42, No. 3, May2014, pp. 652-665

Table 2.

Estimating RLD for bare frame models

\begin{tabular}{|c|c|c|c|c|}
\hline Model ID & $X$ & $\begin{array}{c}\text { RLD } \\
\text { (Time History analysis) } \\
\end{array}$ & $\begin{array}{c}\text { RLD } \\
\text { (Proposed Eq.2) } \\
\end{array}$ & Error \\
\hline 2S_1B8_BF & 228.20 & 10.02 & 11.36 & -1.34 \\
\hline 2S_2B8_BF & 167.79 & 9.06 & 8.78 & 0.28 \\
\hline 2S_3B8_BF & 139.29 & 8.64 & 7.51 & 1.13 \\
\hline 2S_4B8_BF & 121.72 & 8.22 & 6.71 & 1.51 \\
\hline 4S_1B8_BF & 577.66 & 17.49 & 24.73 & -7.24 \\
\hline 4S_2B8_BF & 417.49 & 15.49 & 18.85 & -3.36 \\
\hline 4S_3B8_BF & 343.95 & 14.44 & 16.02 & -1.58 \\
\hline 4S_4B8_BF & 299.32 & 13.61 & 14.26 & -0.65 \\
\hline 6S_1B4_BF & 1197.40 & 52.49 & 45.54 & 6.95 \\
\hline 6S_2B4_BF & 851.11 & 41.67 & 34.22 & 7.45 \\
\hline 6S_3B4_BF & 785.71 & 38.52 & 32.00 & 6.52 \\
\hline 6S_4B4_BF & 656.02 & 36.08 & 27.52 & 8.56 \\
\hline 6S_1B6_BF & 915.20 & 29.46 & 36.36 & -6.90 \\
\hline 6S_2B6_BF & 656.10 & 25.45 & 27.52 & -2.07 \\
\hline 6S_3B6_BF & 538.97 & 23.16 & 23.34 & -0.18 \\
\hline 6S_4B6_BF & 468.34 & 21.96 & 20.75 & 1.21 \\
\hline 6S_1B8_BF & 898.05 & 27.84 & 35.79 & -7.95 \\
\hline 6S_2B8_BF & 702.87 & 23.26 & 29.15 & -5.89 \\
\hline 6S_3B8_BF & 576.03 & 20.83 & 24.68 & -3.85 \\
\hline 6S_4B8_BF & 499.99 & 18.89 & 21.92 & -3.03 \\
\hline 8S_1B8_BF & 1501.61 & 55.15 & 55.05 & 0.10 \\
\hline 8S_2B8_BF & 1068.75 & 48.61 & 41.41 & 7.20 \\
\hline 8S_3B8_BF & 876.05 & 41.82 & 35.06 & 6.76 \\
\hline 8S_4B8_BF & 760.47 & 38.57 & 31.14 & 7.43 \\
\hline 12S_1B8_BF & 2482.86 & 74.26 & 83.88 & -9.62 \\
\hline 12S_2B8_BF & 1944.15 & 68.23 & 68.35 & -0.12 \\
\hline 12S_3B8_BF & 1582.11 & 64.06 & 57.51 & 6.55 \\
\hline 12S_4B8_BF & 1368.10 & 58.88 & 50.92 & 7.96 \\
\hline 16S_1B8_BF & 3425.39 & 108.34 & 109.83 & -1.49 \\
\hline 16S_2B8_BF & 3064.60 & 94.76 & 100.05 & -5.29 \\
\hline 16S_3B8_BF & 2485.75 & 84.82 & 83.96 & 0.86 \\
\hline 16S_4B8_BF & 2145.82 & 78.94 & 74.24 & 4.70 \\
\hline \multicolumn{4}{|r|}{ Standard deviation } & 5.28 \\
\hline
\end{tabular}




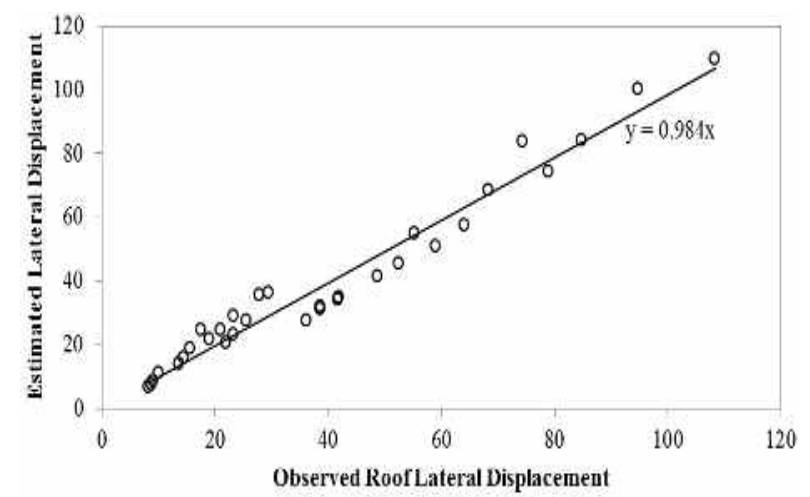

Fig. 5. Relation between Time History Analysis Result and Estimated Roof Lateral Displacement for Bare Frame models

\subsection{Estimating the roof lateral displacement for Infilled Frame models}

For the Infilled frame models the curve of best fit for estimating the roof lateral displacement is shown in Fig.6 with $\left(\mathrm{R}^{2}=0.957\right)$ and the equation is derived as power equation :

$$
\begin{aligned}
& R L D_{I N}=0.003645 *\left(\sqrt{\frac{1}{n_{2}} \cdot \frac{H_{t}}{L_{t}} \cdot \frac{1}{\sum A_{c}}} * D L_{t}\right)^{1.272} \\
& R L D_{I N}=0.003645 *(X)^{1.272}
\end{aligned}
$$

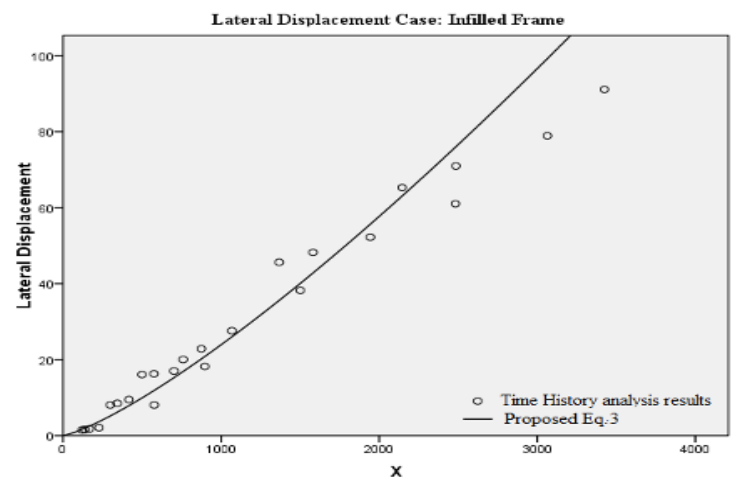

Fig.6. Estimating the RLD for infilled frame models.

Fig.7 and Table 3shows the correlation of estimated value by (Eq.3) with the obtained values, a comparison between the estimated and observed roof lateral displacement for infilled frame models. It is observed that the equation (Eq.3) estimates the values quite accurately and not too far away from the analytical results and this proves the validity of the model. The slope of the trendline between the observed and estimated results was $1.10\left(\theta=47.7^{\circ}\right)$. 


\subsection{Estimating the roof lateral displacement for Open Ground Story Frame models}

For the open ground story models the curve of best fit for estimating the roof lateral displacement is shown in Fig. 8 with $\left(R^{2}=0.904\right)$ and the equation is derived as power equation :

$$
\begin{aligned}
R L D_{O G} & =0.30045 *\left(\sqrt{\frac{1}{n_{2}} \cdot \frac{H_{t}}{L_{t}} \cdot \frac{1}{\sum A_{c}}} * D L_{t}\right)^{0.65256} \\
R L D_{O G} & =0.30045 *(X)^{0.65256}
\end{aligned}
$$

Fig. 9 and Table 4 illustrates a comparison between the estimated and observed lateral displacement for open ground story models. It shows that the estimation equation gives an acceptable accuracy. The slope of the trendline between the observed and estimated results was $0.951\left(\theta=43.56^{\circ}\right)$.

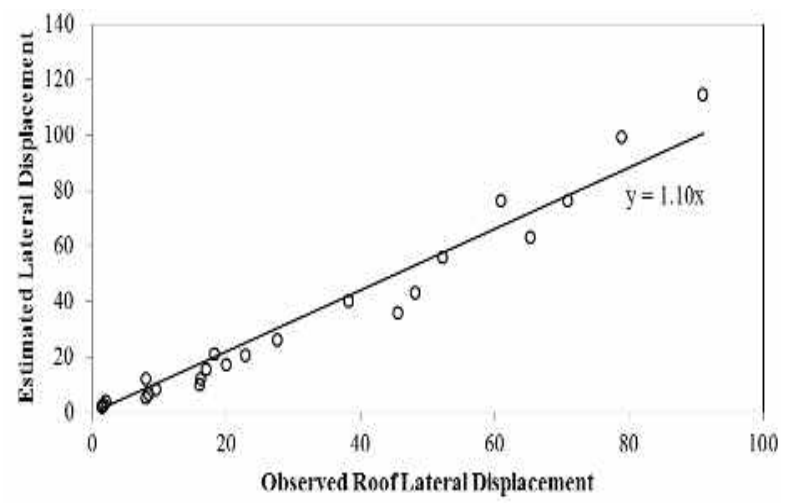

Fig.7. Relation between Time History Analysis Result and Estimated RLD for infilled frame models

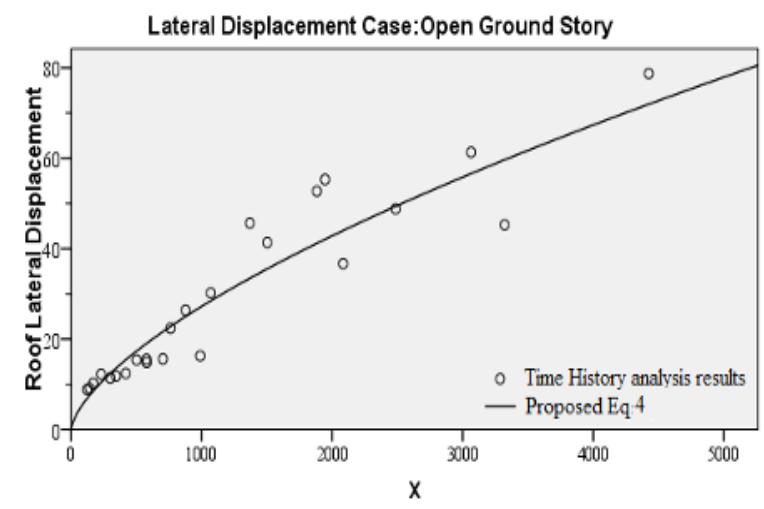

Fig. 8. Estimating the RLD for open ground story models. 
661

Khairy H. Abdelkareem and N. AL-Mekhlafy, Roof lateral displacement for gravity load

Table 3.

Estimating RLD of Infilled frame models

\begin{tabular}{|c|c|c|c|c|}
\hline Model ID & $X$ & $\begin{array}{c}\text { RLD } \\
\text { (Time History analysis) }\end{array}$ & $\begin{array}{c}\text { RLD } \\
\text { (Proposed Eq.3) }\end{array}$ & Error \\
\hline 2S_1B8_IN & 228.20 & 2.07 & 3.64 & -1.57 \\
\hline 2S_2B8_IN & 167.79 & 1.75 & 2.46 & -0.71 \\
\hline 2S_3B8_IN & 139.29 & 1.56 & 1.94 & -0.38 \\
\hline 2S_4B8_IN & 121.72 & 1.46 & 1.64 & -0.18 \\
\hline 4S_1B8_IN & 577.66 & 8.04 & 11.88 & -3.84 \\
\hline 4S_2B8_IN & 417.49 & 9.46 & 7.86 & 1.60 \\
\hline 4S_3B8_IN & 343.95 & 8.47 & 6.14 & 2.33 \\
\hline 4S_4B8_IN & 299.32 & 8.04 & 5.15 & 2.89 \\
\hline 6S_1B8_IN & 898.05 & 18.18 & 20.82 & -2.64 \\
\hline 6S_2B8_IN & 702.87 & 16.98 & 15.24 & 1.74 \\
\hline 6S_3B8_IN & 576.03 & 16.26 & 11.83 & 4.43 \\
\hline 6S_4B8_IN & 499.99 & 16.05 & 9.88 & 6.17 \\
\hline 8S_1B8_IN & 1501.61 & 38.2 & 40.03 & -1.83 \\
\hline 8S_2B8_IN & 1068.75 & 27.57 & 25.98 & 1.59 \\
\hline 8S_3B8_IN & 876.05 & 22.84 & 20.17 & 2.67 \\
\hline 8S_4B8_IN & 760.47 & 20.01 & 16.85 & 3.16 \\
\hline 12S_1B8_IN & 2482.86 & 61 & 75.90 & -14.90 \\
\hline 12S_2B8_IN & 1944.15 & 52.2 & 55.60 & -3.40 \\
\hline 12S_3B8_IN & 1582.11 & 48.19 & 42.78 & 5.41 \\
\hline 12S_4B8_IN & 1368.10 & 45.6 & 35.56 & 10.04 \\
\hline 16S_1B8_IN & 3425.39 & 91.09 & 114.29 & -23.20 \\
\hline 16S_2B8_IN & 3064.60 & 78.89 & 99.20 & -20.31 \\
\hline 16S_3B8_IN & 2485.75 & 70.95 & 76.01 & -5.06 \\
\hline 16S_4B8_IN & 2145.82 & 65.26 & 63.04 & 2.22 \\
\hline \multicolumn{4}{|r|}{ Standard deviation } & 5.86 \\
\hline
\end{tabular}


JES, Assiut University, Faculty of Engineering, Vol. 42, No. 3, May2014, pp. 652-665

Table 4.

Estimating RLD of open ground story models

\begin{tabular}{|c|c|c|c|c|}
\hline Model ID & $\mathrm{X}$ & $\begin{array}{c}\text { RLD } \\
\text { (Time History analysis) }\end{array}$ & $\begin{array}{c}\text { RLD } \\
\text { (Proposed Eq.4) }\end{array}$ & Error \\
\hline 2S_1B8_OG & 228.20 & 12.25 & 10.39 & 1.86 \\
\hline 2S_2B8_OG & 167.79 & 10.19 & 8.50 & 1.69 \\
\hline 2S_3B8_OG & 139.29 & 9.14 & 7.53 & 1.61 \\
\hline $2 \mathrm{~S} \_4 \mathrm{~B} 8 \_\mathrm{OG}$ & 121.72 & 8.84 & 6.90 & 1.94 \\
\hline 4S_1B8_OG & 577.66 & 14.83 & 19.05 & -4.22 \\
\hline 4S_2B8_OG & 417.49 & 12.42 & 15.41 & -2.99 \\
\hline 4S_3B8_OG & 343.95 & 11.82 & 13.58 & -1.76 \\
\hline 4S_4B8_OG & 299.32 & 11.4 & 12.41 & -1.01 \\
\hline 6S_1B8_OG & 988.05 & 16.28 & 27.04 & -10.76 \\
\hline 6S_2B8_OG & 702.87 & 15.63 & 21.65 & -6.02 \\
\hline 6S_3B8_OG & 576.03 & 15.54 & 19.02 & -3.48 \\
\hline 6S_4B8_OG & 499.99 & 15.39 & 17.34 & -1.95 \\
\hline 8S_1B8_OG & 1501.61 & 41.37 & 35.54 & 5.83 \\
\hline 8S_2B8_OG & 1068.75 & 30.22 & 28.46 & 1.76 \\
\hline 8S_3B8_OG & 876.05 & 26.39 & 25.00 & 1.39 \\
\hline 8S_4B8_OG & 760.47 & 22.39 & 22.80 & -0.41 \\
\hline 12S_1B8_OG & 2082.86 & 36.71 & 44.00 & -7.29 \\
\hline 12S_2B8_OG & 1944.15 & 55.3 & 42.06 & 13.24 \\
\hline 12S_3B8_OG & 1882.11 & 52.7 & 41.18 & 11.52 \\
\hline 12S_4B8_OG & 1368.10 & 45.65 & 33.44 & 12.21 \\
\hline 16S_1B8_OG & 4425.39 & 78.73 & 71.94 & 6.79 \\
\hline 16S_2B8_OG & 3064.60 & 61.33 & 56.60 & 4.73 \\
\hline 16S_3B8_OG & 2485.75 & 48.8 & 49.38 & -0.58 \\
\hline 16S_4B8_OG & 2145.82 & 51.7 & 44.90 & 6.8 \\
\hline \multicolumn{4}{|r|}{ Standard deviation } & 6.02 \\
\hline
\end{tabular}




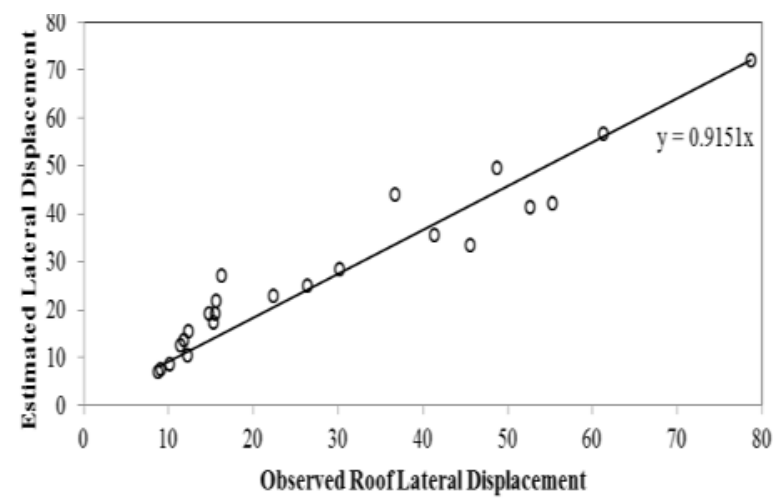

Fig. 9. Relation between Time History Analysis Result and Estimated RLD for open ground story models

\section{Conclusion}

The data obtained from the time history dynamic analysis for a series of GLD RC frame was used as input data in a statistical program called SPSS, and a statistical analysis was done and a power equations was proposed to estimate the roof lateral displacement for the GLD RC frames. Three equations were proposed for estimating the roof lateral displacement, the first one is for the bare frame models, the second is for infilled frame models and the third is for infilled frame with open ground story. It was observed that the equations proposed estimates the values quite accurately and not too far away from the analytical results and this proves the validity of the model. The slope of the trendline between the observed and estimated results for the three equations was $0.984\left(\theta=44.54^{\circ}\right)$, $1.10\left(\theta=47.7^{\circ}\right)$ and $0.951\left(\theta=43.56^{\circ}\right)$.

\section{REFERENCES}

[1] C. V. R. Murty, S. Brzev, H. Faison, C. D. Comartin, and A. Irfanoglu, AT RISK: The Seismic Performance of Reinforced Concrete Frame Buildings with Masonry Infill Walls. Earthquake Engineering Research Institute, Oakland, California, 2006.

[2] M. A. Al-masni, "Earthquake Building Risk Assessment in Sana'a City, Yemen," Final Report, Asian Disaster Reduction Center, 2012.

[3] S. E. Abdel Raheem, "Evaluation of Egyptian Code Provisions for Seismic Design of Moment-Resisting-Frame Multi-Story Buildings," International Journal of Advanced Structural Engineering, vol. 5, no. 3, pp. 20-34, 2013.

[4] M. Galli, "Evaluation of the Seismic Response Of Existing R.C. Frame Buildings With Masonry Infills," PhD Thesis, University of Pavia, Italy, 2006.

[5] Ö. Çavdar and A. Bayraktar, "Pushover and Nonlinear Time History Analysis Evaluation of a RC Building Collapsed During the Van (Turkey) Earthquake on October 23, 2011," Natural Hazards, 05-Sep-2013. [Online]. Available: http://link.springer.com/10.1007/s11069-013-0835-3. [Accessed: 18-Oct-2013].

[6] S. A. ALSinawi and A. Al Aydrus, Seismicity of Yemen. Obadi Studies \& Publishing Center, Sana'a, Republic Of Yemen, 1999.

[7] A. Awad, H. Bassam, and I. Talal, "Moment Resisting Frame Designed for Gravity Loads Only," World Housing Encyclopedia, an initiative of Earthquake Engineering Research Institute (EERI) and International Association for Earthquake Engineering (IAEE). 2002. 
[8] V. Pascucci, M. W. Free, and Z. A. Lubkowski, "Seismic Hazard and Seismic Design Requirements for the Arabian Peninsula Region," in The 14th World Conference on Earthquake Engineering. October 12-17, 2008, Beijing, China.

[9] K. H. Abdelkareem, F. K. Abdel-SaAyed, and N. AL-Mekhlafy, "Some Parameters Affecting The Behaviour of R.C. Frames Designed for Gravity Loads Only and Subjected To Earthquakes,” Journal of Engineering Sciences, vol. 42, no. 1, pp. 93-111, 2014.

[10] SPSS Statistics Base 16 . O User's Guide. SPSS Inc. Chicago, USA, 2007.

[11] ACI Comminee 318, "Building Code Requirements for Reinforced Concrete (ACI 31889)'," AmericanConcrete Institute, Detroit. 1989.

[12] K. H. Abdelkareem, F. K. Abdel-SaAyed, M. H. Ahmed, and N. AL-Mekhlafy, "Equivalent Strut Width For Modeling R.C. Infilled Frames," Journal of Engineering Sciences, vol. 41, no. 3, pp. 851-866, 2013. 


\section{الازاحة الافقية عند السطح للاطارات الخرسانية المسلحة}

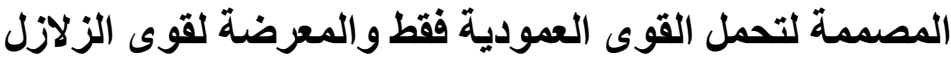

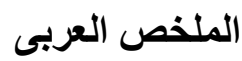

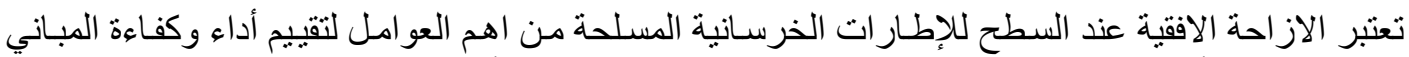
هندسياو يجب أن تكون ضمن حدود مقبولة وفقا لمتطلبات مستويات الأداء المختلفة. تم استخدام قيم الاز احات التهات

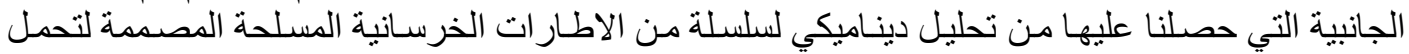

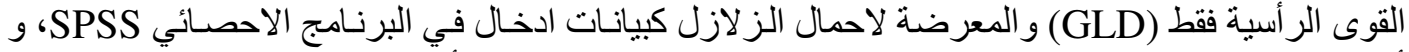

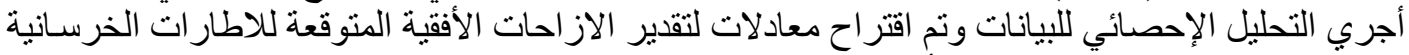

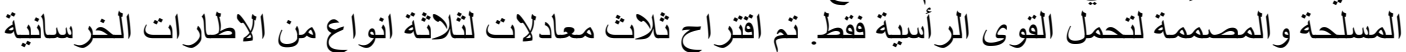

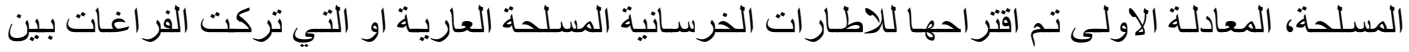

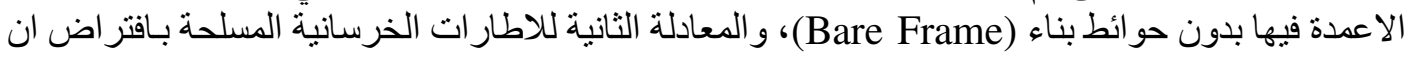

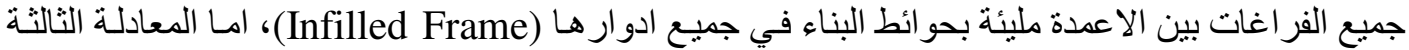

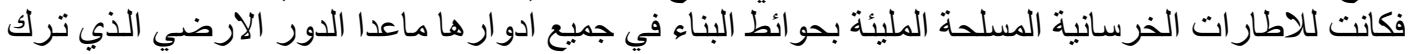

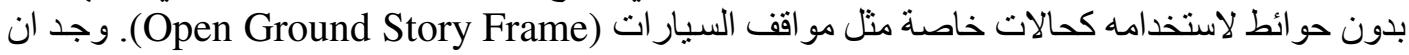

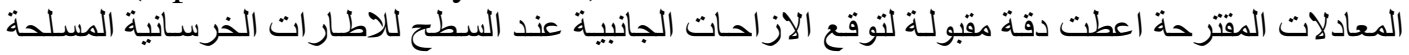

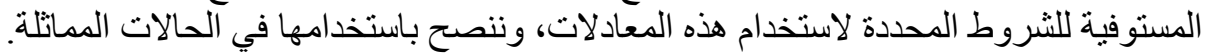

